\title{
Time Experience of Burnout Patients: A Qualitative Diary Analysis
}

Andrea Paletta ${ }^{1 \star}$, Gerald Suchar ${ }^{2}$, Theresa Hübler ${ }^{1}$, Daniela Juschitz ${ }^{1}$, Katharina Mayer ${ }^{1}$ and Jana Staltner ${ }^{1}$

${ }^{1}$ Movement and Sports Pedagogy Research Group, Institute of Sports Science, University of Graz, Graz, Austria

${ }^{2}$ Private Clinic of St. Radegund, St. Radegund, Styria, Austria

\begin{abstract}
Background: The burnout phenomenon appears to be a health-economics problem in many industrialized countries. Alongside well known causes, such as job related or personality-specific factors, the connection between burnout and the experience of time is being focused on increasingly by researchers. Biological as well as social and psychological processes are based on individual rhythms and time management, which are dysregulated in case of burnout patients. Therefore it is relevant to clear up the question of the subjective experience of time.

Materials and Method: In terms of relevant subjective experience of time, literature differentiates between the experiences of personal time (biological rhythm or presence of time), of intersubjective time (coordination of time between subjects), and one's own personal driving force (a vital inner force that actually generates actions). This phenomenological concept is used as a base for an empirical investigation.

Methods: Goal of the study is to explore the subjective time experience of 22 burnout patients (aged $\phi 47.2 \pm 9.1$ years) in a psychiatric rehab clinic and of 22 healthy sports students (aged $\phi 23 \pm 1$ years) during a four week period. Adequate method is the diary analysis (qualitative exploration study), in form of a semi-structured guideline interview, in which various subjective perspectives can be taken into consideration. Main topics are the above-mentioned dimensions of time: personal time (rhythm), intersubjective time (giving and taking time, intersubjective reconcilement) and driving force (effort). Dataset includes 1936 statements, which were analysed by the structuring content analysis acc. Mayring. Results:

Personal time: Initially, burnout patients complain intensively about negatively experiencing their circadian rhythm. After four weeks, half of the patients report a stabilisation and they discover the pleasant effect of rhythmic sports.

Intersubjective experience of time: people suffering from burnout do not achieve a balance between giving and taking - taking time for themselves is considered as something positive, giving time as extremely exhausting. After four weeks spending time with others is declared rather as an enrichment.

Driving force: Burnout patients develop almost no driving force- their physical and mental rhythm, as well as all forms of effort are designated entirely as negative.

Conclusion: Initially burnout patients, when compared to the healthy control group of sports students, show remarkable deregulations concerning all time dimensions. However, during a four week period, their time patterns can approximate those of healthy people. Movement and sports are declared as important measures in order to stabilise biological and psychosocial time patterns. The mentioned perspectives of time could be used as a base for a specific adapted sports therapy concept.
\end{abstract}

\section{Background/ Introduction}

Burnout is increasingly becoming a problem for the economy of many industrialized countries - almost 13 Mill. employees in Germany were affected by the disease in 2014 and sick days have risen from 2004 to 2011 nineteen-fold [1,2]. According to medical classification systems, burnout is not defined as a distinct disorder but rather as a health problem, listed in the ICD-10 (Z73) under problems and difficulties related to life-management. Nevertheless, the term burnout can be summed up by a specific cluster, which Burisch [3] describes as fundamental fatigue, absolute exhaustion and the feeling of losing control. The main deficit is a decline in capacities for self-organisation. It manifests itself through the inability of making decisions, reduced flexibility in the handling of changing challenges, decline in cognitive productivity, flattening of emotional involvement and an increasingly negative attitude towards oneself and the environment [4]. Also physical dysregulations are an issue, including sleep disturbances, cardiovascular disorders, breathing difficulties, muscle and tendon pain and a weakened immune system.

\section{Publication History:}

Received: September 09, 2016

Accepted: January 31, 2017

Published: February 02, 2017

\section{Keywords:}

Burnout patients, Sport students, Time experience, Qualitative diary analysis, Movement and sports activities
This development ends in a lack of feeling of existence as well as meaning of life, leading to a feeling of inner emptiness and existential despair. According to Maslach et.al. [5], three main dimensions of these symptoms can be summed up as follows: (a) emotional exhaustion (e.g. fatigue and meaninglessness), (b) depersonalisation (e.g. setting aside personal interests as well as interactions with the environment) and (c) inefficacy, reduced personal accomplishment which results in an initially only feared but increasingly real-noncompliance of tasks and duties.

*Corresponding Author: Dr. Andrea Paletta, Movement and Sports Pedagogy Research Group Institute of Sports Science, University of Graz, Mozartgasse 14 A-8010 Graz, Austria; E-mail: andrea.paletta@uni-graz.at

Citation: Paletta A, Suchar G, Hübler T, Juschitz D, Mayer K, et al. (2017) Time Experience of Burnout Patients: A Qualitative Diary Analysis. Int $\mathrm{J}$ Phys Ther Rehab 3: 126. doi: https://doi.org/10.15344/2455-7498/2017/126

Copyright: ( 2017 Paletta et al. This is an open-access article distributed under the terms of the Creative Commons Attribution License, which permits unrestricted use, distribution, and reproduction in any medium, provided the original author and source are credited. 
The causes of burnout are multifactorial in origin: on the one hand job-related aspects play a role, such as working pressure, bullying and lack of decision-making authority and independence [5]. On the other hand, personality-specific factors, such as insufficient self-confidence, overly high need for control, excessive urge for recognition and a lack of conflict resolution skills [6,7], as well as problems with the coordination of individual resources and environmental demands, could also be found [8].

Only recently, the connection between burnout and time has been attracting more attention. Dimensions of time are increasingly being focused on across all disciplines (Psychology [9, 10, 11], Sociology $[12,13]$, Philosophy [14, 15], Chronobiology [16, 17]). Health dysfunctions are now thought of as a result of an accelerated modern civilisation and humans are being localised through a so-called "Cronokratie" [18], a dictatorship of timetables, which leads them to an excessive flexibility and mobility $[12,13]$. As a reaction, several measures concerning time management in companies are being taken, such as reduced work pace, a larger number of breaks and adequate working rhythm for all employees [19].

However, it still needs to be clarified, how people, affected by the burnout syndrome, organise their time and how they individually manage their time in general. The subjective experience of time, or of process-related change, provides fundamental parameters for the organisation and orientation of the self. Therefore, experience of time for biological, as well as psychological processes, is a central component in terms of imprinted biological rhythms (heart beat, sleep-wake rhythm, breathing rhythm) and also considering decisions based on individual rhythm and effective time management.

According to the theories by Pauleikhoff [20], Klages [21], Wölk [22] and Fuchs [23], mental illness and specific depressions are generally affected by deregulations of time. Therefore, also in terms of burnout, further analysis of the issue could lead to a clearer picture of the dynamics [25].

\section{Materials}

In terms of relevant subjective experience of time, Fuchs [23] differentiates between the experiences of personal time (Eigenzeit) intersubjective time (Intersubjektive Zeit) and one's own personal driving force (eigener Antrieb).

As Burnout can be seen as a process, sometimes lasting many years, the range of symptoms always depend on the duration and severity of the illness. Even negative social consequences can be linked with the syndrome, such as, from the point of view of the individual, withdrawal at the workplace (so called 'inner resignation') or effects on private life (partner/ sexual problems, social isolation). From the perspective of society, there is an increased risk of repeated or long periods of absence from work and early invalidity [7].

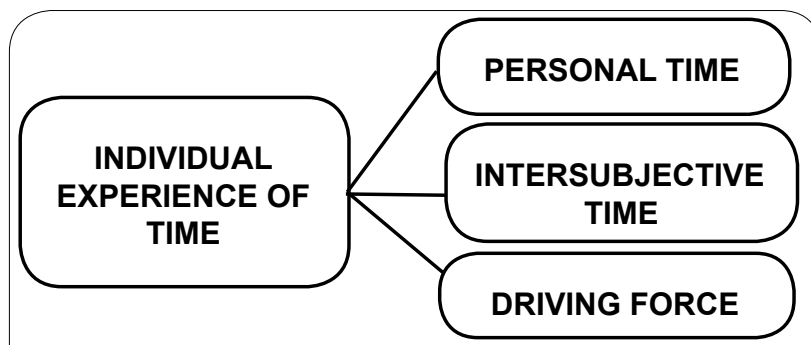

Figure 1: Subjective experience of time [cf.23,25]
Personal time (Eigenzeit) can be experienced daily in any kind of biological rhythm, such as breathing rhythm, digestive rhythm, heartbeat and sleep-wake rhythm. Furthermore, it can also be found in pulse-triggered acting, in the living in the moment, the act of losing oneself and forgetting time and space. This act goes along with the experience of flow [24], meaning that the actor is living the moment, detached from any temporal circumstances, expressing herself through her individual way of life and in her very own time. By contrast, the experience of personal time loss goes along with deregulations of vital rhythms (e.g. insomnia, jetlag, lacking balance between periods of activity and periods of rest, irregular breathing) and conscious reflection of time (e.g. concerns about time pressure, realizing the limited availability of time). It also takes place in the course of time compressing activities (doing several things at the same time, e.g. making a call and writing) as well as boring and meaningless actions (killing time, routine work), where the actor is barely emotionally involved and thus not in control of her course of actions $[\mathrm{cf} .23,25]$.

Unsurprisingly, especially the experience of other-directed time has become the norm in terms of burnout - the balance between otherdirected and individual time undergoes a shift in favour of fixed dates. In the course of interviews or personal testimonials by people suffering from burnout, Paletta [25] has demonstrated the consequences of the loss of individual time: complaints about biological rhythm disorders ,...Everything is turning...my head is buzzing. My breathing is shallow. I experience a pinching in my tummy and my back. My heart is pounding as if it was about to burst..."[26] $]^{1}$. They also complained about lacking presence of mind (Gegenwartspräsenz) „She is constantly thinking about the next meal, before even starting to eat this one" (patient reporting about another burnout patient [27]) and about useless and meaningless routine acting "It is strange how meaningless the world can become. I have lost touch with reality... everything seems so far away" [28, cf. 25].

A further dimension-the experience of intersubjective time (intersubjektive Zeit)-is, according to Fuchs, being processed through the coordination of time between subject and environment. In this context, two types of experience are possible: synchronization, meaning that the subject interacts with the environment, oscillates with it in time and adapts to its rhythm. The second type of experience is desynchronization, a break between individual time and that of the environment - a result of apparently incompatible processes of action or rhythms [cf.23, 25].

Even though their own rhythms might be blocked, it is verified that those suffering from burnout contain an immense desire for synchronization within themselves:

„I fall very quickly into this externally-controlled "join-in mode" [29]

The reasons are widely varied: for example because devotion to the environment includes a feeling of obliviousness (similar to the flow), because defined time structures organize life and are therefore often welcomed, or because a common rhythm creates a feeling of a deeper connection and security (e.g. dandling infants, military marches). Obviously, the person concerned overlooks the fact that repeated attempts to adapt to others' needs will end in insufficient individual time management. „...5 minutes: I have tried to catch up on my e-mails, at the same time a workmate comes to my office and needs help.

This statement and the following are translated by the author. 
Citation: Paletta A, Suchar G, Hübler T, Juschitz D, Mayer K, et al. (2017) Time Experience of Burnout Patients: A Qualitative Diary Analysis. Int J Phys Ther Rehab 3: 126. doi: https://doi.org/10.15344/2455-7498/2017/126

Page 3 of 7

Concurrently, a colleague calls and asks about when I would come to the meeting... " [30] Various demands of the environment fragment "the time that the personal life-process is trying to follow; it is being scrambled and multiplied until only rudiments remain, i.e. actions that spread to all four corners of the world, without being based on own drive and without aim" [25].

As the third dimension, Fuchs [23] describes the inward urge (innerer Antrieb), a vital inner force that actually generates action. This concept does not refer to a rational power of persuasion but rather to an elementary power that influences all types of motor, sensory and associative performances. Basically, it is a psychological fundamental function, ranging through all fields of human life and experience [31]. The extent of a vital driving force depends on three factors: physical form and state of mood, preferences (instincts, biographical influences, interpretations, values, motives) and the environment and atmosphere in which the human being is acting (the more favourable the external circumstances, the better the vital driving force - the more confining the environment, the more the human being is narrowed. All the mentioned factors are closely interlinked - the more the person in concern is exhausted, the less inward urge will she invest in her acting, the less sense will be generated or - vice versa if senseless actions are being forced, the inner resistance will lead to a decimation of energetic resources. In the long-term, such actions lower the inward urge and physiological as well as psychological motivation [cf. 23, 25].

So far, the experience of time was described from a phenomenological point of view and shall now be validated empirically. Besides the inquiry of patterns in personal experience of time of burnout patients, it shall also be analysed how stable these patterns are and in how far they are accessible to interventions and measures in rehab clinics.

\section{Methods}

As already announced, the aim of this investigation is to explore burnout patients and their personal experience of time through their stays in a rehab clinic. The main focus lies on subjective experience. Standardised measurement is not suitable for this kind of study: it is unlikely that all possible perspectives of the people in concern can be taken into account beforehand when designing relevant questions. However, a qualitative analysis in form of an exploration study is an adequate method where various subjective perspectives can be taken into consideration. In order to present a variety of statements, which does not only confirm the existence of a great complexity of time patterns but also examines them, a survey period of four weeks rather than one single investigation point was chosen. In this period, possible changes and new points of view in terms of experience of time can be made transparent. The suitable measurement is the diary method, combining the following advantages [32]

Presentation of individual and subjective data information

Personal experiences are collected chronologically over a longer period of time

Subjective experiences are written down - sorted, organized, structured - and thereby made accessible for reflective revision

Enables following processes continually and therefore also detecting changes

The connection between awareness and acting is being recorded, i.e. observations and actions are relatable to one another
Furthermore, the diary has also a positive effect on the patients themselves - it can become a "relief in facing the personal mental state, critical events, disorders and crises"

Based on the time dimensions stated in chapter "materials", the present diary is constructed as a semi-structured guideline interview: questions about personal time (personal rhythm and presence of mind, handling breaks), about intersubjective experience of time (intersubjective relations, feedback with the counterpart) and about inward urge (its extent, economy and effort). Each of these questions is associated with several impulse questions, which are, however not mandatory: participants are welcome to state their own opinion.

Following, three out of nine questions in total are presented exemplarily:

Personal time-rhythm: Did you stick to your rhythm this week? Could you sleep well and be active afterwards? Was your breathing regular, agitated or constrained? What about your digestion and your heartbeat? Did you experience any difficulties finding your own rhythm because of an interfering external rhythm? Which health effects did you notice?

Intersubjective experience of time: Did you give yourself a treat this week? What satisfied you the most? What do you wish you would have spent more time doing? Could you keep the balance of giving and taking? Did you give too much of a good thing and receive too little of the essential? Have your feelings changed? Do you see any connections with your available time budget?

Driving force-effort: Do you remember any situations this week exerting yourself? What kind of situations were these? How did you feel? Did you meet your goals? In which situations did you rack yourself? Are there any personal reasons for that?

\section{Sample and implementation}

The study examined 22 burnout patients ( 13 men and 9 women, age $\phi 47.2 \pm 9.1$ years) in a psychiatric clinic (St. Radegund Private Clinic, Styria/Austria). This included volunteering participants whose doctors had diagnosed them with burnout syndrome and who had additionally been diagnosed with burnout in terms of the BOSS diagnostic instruments I-III [33], who had not been hospitalised for more than one week at the start of measurements, and who were not confined to the bed.

The intervention supports burnout patients through talking therapy, occupational therapy, musical therapy and sports therapy. Between January and May 2015, the pre-printed diary templates were distributed to three different groups of patients each week and they were asked to complete their diary entries on a fixed day of the week. They were instructed to reflect on their experiences during the previous week, mainly regarding experience of time that they remembered especially vividly. The completed diary from the week before was collected.

According to Mayring [34], qualitative explorative methods do not need a control group, nevertheless, further comparative data was collected: with namely 30 students of the sports faculty of the local university (18 men, 12 women, aged $\phi 23 \pm 1$ ) an extreme counterpart

${ }^{2}$ This statement and the following are translated by the author.

${ }^{3}$ The diary also contains questions about body awareness and a standardised investigation parts, however, both are not included in this paper. 
Citation: Paletta A, Suchar G, Hübler T, Juschitz D, Mayer K, et al. (2017) Time Experience of Burnout Patients: A Qualitative Diary Analysis. Int J Phys Ther Rehab 3: 126. doi: https://doi.org/10.15344/2455-7498/2017/126

Page 4 of 7

to burnout patients was deliberately chosen. As sports can be considered as an "experimentation lab" for time management, sports students have intensive and extensive experience with the issue of time [cf. 35]. Athletic success requires an efficient and long-term training plan, the implementation of athletic goals (e.g. scored goals) in a fixed period of time, and in case of some sports disciplines speed determines whether you win or lose. In the course of optimisation strategies, athletes often face modern phenomena of experience of time, namely acceleration and time compressing. Sport also offers the possibility of fixing individual time models, for example via personal rhythm during cyclical sport activities (e.g. jogging, swimming), coordination between personal and external rhythm of movement (e.g. dancing), or the living of the moment and thereby experiencing personal time (Eigenzeit) (e.g. surfing) [35].

The data on sports students was collected at the Department of Sports Science Graz in the period between October and November 2014. The method was applied as illustrated first: students recorded their experience of time in pre-printed diary templates. [36] After four weeks of collecting data, the whole set of records of burnout patients and sports students includes more than 1936 statements which were transcribed. Afterwards the data were analysed by the structuring content analysis acc. Mayring, i.e. each individual comment was reduced to his core message and categorized semantically [35, 37-40].

\section{Results and Discussion}

Not all results can be illustrated in this article. However, those of the second week of investigation are being presented below, because at that point unintended side effects of newly arrived burnout patients had died down, also the results of the forth week, when patients had almost finished their therapy. ${ }^{4}$ The variety of statements about different time dimensions is listed hereafter. Letters and numbers in round brackets indicate the person giving the statement.

\section{Personal time, rhythm}

It is clearly evident that statements made by burnout patients about experience of rhythm are mainly negative. They are complaining

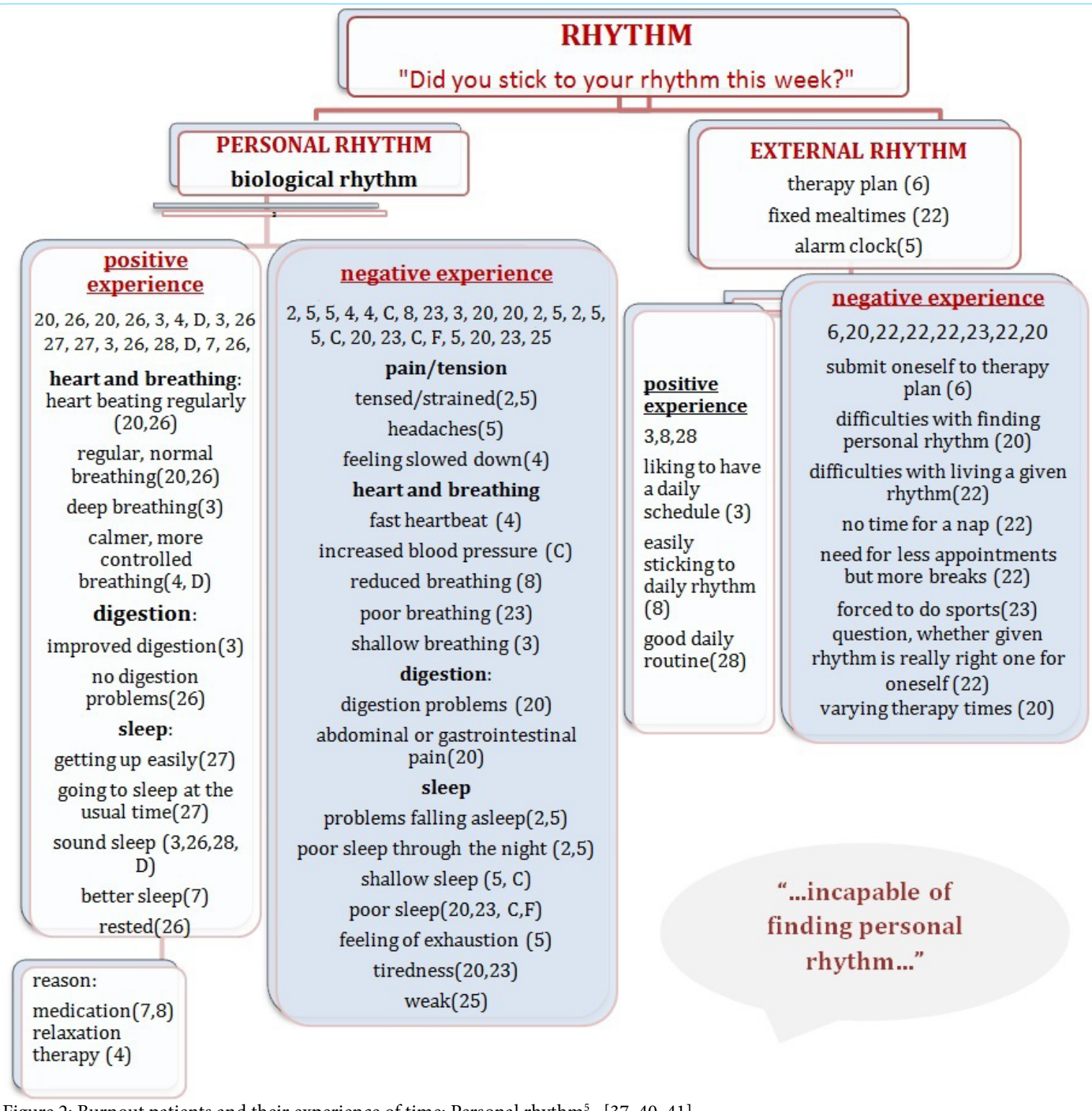

Figure 2: Burnout patients and their experience of time: Personal rhythm ${ }^{5}[37,40,41]$.

Comments of burnout-patients and sports students are translated by the author 
Citation: Paletta A, Suchar G, Hübler T, Juschitz D, Mayer K, et al. (2017) Time Experience of Burnout Patients: A Qualitative Diary Analysis. Int J Phys Ther Rehab 3: 126. doi: https://doi.org/10.15344/2455-7498/2017/126

about lack of personal rhythm, stating that they "feel slowed down ... and incapable of doing something against it" (4), and "....incapableof finding personal rhythm.... However, they are also criticizing the outside pressure, such as being requested to stick to fixed daily structures, e.g. "submitting oneself to therapy plan" (6) and having "no time for a nap", or questioning themselves whether "given rhythm in the clinic is the best one for themselves" (22). Also, the experience of the biological rhythm is negative, concerning dysfunctions of all organs: cardiovascular system ("faster heartbeat"), breathing ("fast, poor, shallow, reduced" $4,8,23,3$ ), digestion, muscular system (constantly "feeling strained" 5) and mainly the sleep-wake rhythm ("poor sleep through the night, feeling of exhaustion, tiredness, weakness" 2, 5, 20, 23, 25). Significantly fewer burnout patients report about rhythms that work well. According to them, the reasons for this are medicines and relaxation therapy $(4,7,8)$.

Statements given by sports students show predominantly positive experiences: apart from the fact that reports focus mainly on personal rhythm, they also inform about "a healthy balance between daily chores and well-being" (M), about balanced biological rhythms such as sleep, breathing and digestion. These can be interpreted as the result of conscious rejection of external rhythms: "refusing another rhythm that does not fit the concept" (F, J). Also, they can be considered as the ability to adjust requirements to make them compatible with the personal rhythm "I could stick to the rhythm, even though it was a busy week", or as the ability to use environmental requirements constructively as a time base: "leveraging everything" $(\mathrm{N})$.

After five weeks of therapy, burnout patients report more positively about their biological rhythm. However, they still complain about digestion, breathing and sleeping problems. Almost half of the patients state that they have found their own rhythm. "Since I have stepped back, I stick more to the rhythm. I feel calmer, can relax more easily, breathe better, do not pant any more" (5) (transl. by author). Also appointments fixed by the clinic are now accepted, proving suitable adaptation strategies of burnout patients [cf.37, 40].

Findings concerning sports students show mainly positive experiences throughout each of the four weeks [cf. 38, 39]. The reasons given for the few occasions when their personal rhythm is upset are: specific appointments, diseases and leisure time filled with too many activities.

\section{Intersubjective experience of time, giving and taking}

Looking at figure 4, it becomes evident that burnout patients generally give more importance to taking than giving. A typical statement would therefore be: "Hard as it may sound, for the first time I am looking after myself" (23). The reason why they are now taking time just for themselves are apparently social issues, e.g. "support by group colleagues" (24), "positive feedback" (4) or "individual

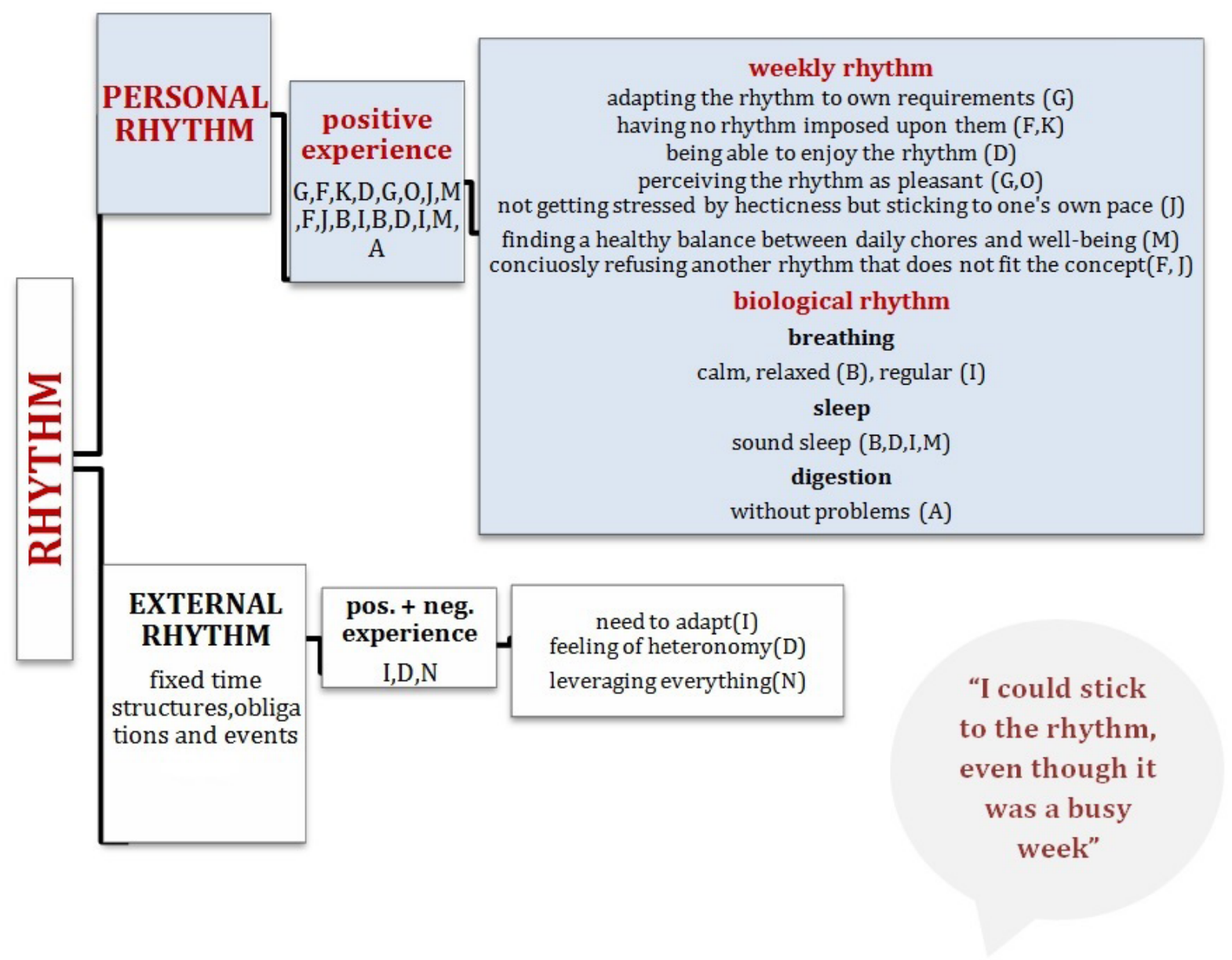

Figure 3: Sports students and their experience of time: Personal rhythm [38, 39, 42].

${ }^{4}$ In principle the data of week one and three does not differ from week two and

four in terms of content, but in terms of extent (fewer statements). 
Citation: Paletta A, Suchar G, Hübler T, Juschitz D, Mayer K, et al. (2017) Time Experience of Burnout Patients: A Qualitative Diary Analysis. Int J Phys Ther Rehab 3: 126. doi: https://doi.org/10.15344/2455-7498/2017/126

Page 6 of 7

conversations" (21). However, they also mentioned reasons for engaging in active relaxation, such as "building-up muscle mass" (7), "going for a walk" (20), "reading" (23), but also measures regarding passive consumerist relaxation, e.g. "taking a footbath", "watching TV" or "eating regularly" $(6,3,23)$. Furthermore, burnout patients are consciously working on modulating their own personal attitudes, e.g. "taking time for oneself", "looking after oneself", or "allowing oneself to be alone" $(22,23,26)$. The experiences of taking are only positive, e.g. "it feels (very) good" $(3,21,22)$, "it is pleasant", "nice", "is fun" or "overjoyed" $(23,25,27)$, supports the feeling of "relaxation" and "drawing strength" (25). Sceneries of giving are mentioned rarely and the experience of it is rather negative. Burnout patients experience issues such as "giving time" (4), "listening actively" (8) or "giving joy and calmness to others" (27) as stress. They have "no more strength to give" (23), "feel burnt out and empty" (5), and it is getting "more and more exhausting" (5). Unlike sports students (see below), burnout patients are lacking a balance between giving and taking.
Among students of the sports faculty, the balance of giving and taking is the main category in terms of their intersubjective experience of time. It includes social activities with family members (F,I,M,L), or friends or partners $(\mathrm{F}, \mathrm{M}, \mathrm{K})$. The feeling of togetherness therefore often involves the physical level, e.g. "swimming", "hiking", "massage" $(\mathrm{I}, \mathrm{L}, \mathrm{H})$. A typical statement such as "this week, giving and taking are in balance" (D) is associated with positive experiences, such as "good", "enriching" or "relaxing" (H,A,B,E,O). In stark contrast to burnout patients, also experiences of giving are positive. Sports students state that they "liked doing them" $(\mathrm{H})$ or did not have a "feeling of (investing a) bigger effort" (J), for examplewhen they engaged in social activities such as providing "emotional support to the partner" and "visiting family" (O, N). Also,making time for oneself seems to be important for sports students, especially for sports activities (e.g. "work out" (F,G,H,I) or "dancing" (L) ). Furthermore, relaxing measures are also important so as to quickly rebuild inner balance, such as "time for quiet and breaks", "good meals" (L) or a "hot bath" (H). Even though

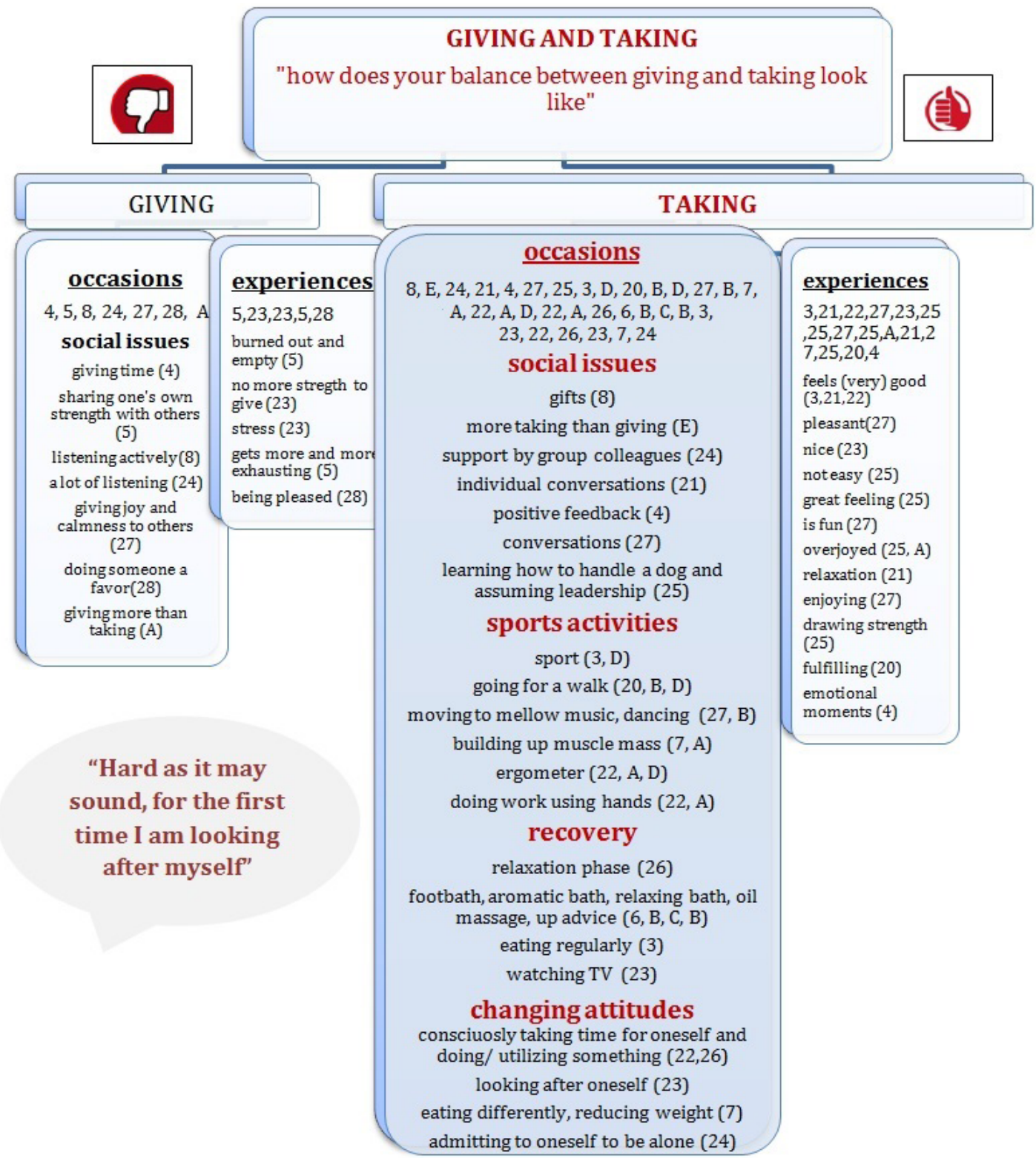

Figure 4: Burnout patients and intersubjective experience of time: giving and taking [37, 40, 41]. 
Citation: Paletta A, Suchar G, Hübler T, Juschitz D, Mayer K, et al. (2017) Time Experience of Burnout Patients: A Qualitative Diary Analysis. Int J Phys Ther Rehab 3: 126. doi: https://doi.org/10.15344/2455-7498/2017/126

Page 7 of 7

sports people buckle down and might even make sacrifices, they also know when to take a step back in order to regain their balance [cf. 36].

Even at the end of their rehabilitation stay, taking remains the most important category in burnout patients. However, sports activities have gained importance and positive experience is connected to the condition of the body, e.g. "does the body good" (2), one of the main concerns is "looking after the body and oneself" (5). This might be the result of sports therapy during several weeks $[37,40]$.

During the four weeks, sports students do not change their selfimage. They keep their balance between giving and taking and their attitude towards life remains associated with positive body experience: "...somebody else would probably interpret the workout as "giving", namely "I have to do something in order to stay healthy", but I experience it as releasing and feel more comfortable afterwards ..." (M) $[38,39]$.

\section{Intersubjective time: reconcilement}

The answers about intersubjective reconcilement or intersubjective response are noteworthy: burnout patients report mainly positive experiences. The reasons for this are conversations with each other, but also social demarcations or common activities like sports.
The answers suggest that burnout patients enjoy getting feedback and are consciously searching coordination with others. Experiences are rather pleasant: they feel "motivated", "it is fun", they have "laughed a lot", are "filled with joy and happiness", are "relaxed" and "feeling themselves" $(6,26,2,20,27,24)$. If the group is mentioned as the source of experiences, it is apparent that the interviewed persons do not mainly report on joint experiences but focus on the group's attitude towards their own self. This is proven by statements such as "I was sheltered by the group" (7), "colleagues have shown understanding" (25) and "growing trust in the group" (8). This is perfectly represented by the following statement: "Now I can see that other persons are interested in how I feel" (3). The attention lies rather on the subject using the group as a reflection of herown state, rather than joint experiences. Therefore, negative experiences often go along with conversational situations in which the subject feels negated: "one-sided conversation", "constant talker - not listening to others" (3), overwhelmed - "too much conversation" (5) and feeling "verbally attacked by group members". Altogether, encounters based on verbal conversation are often described as energy sapping: "After conversations I always feel tired. I am taking on too much work and not looking after myself. As soon as I feel energetic, I invest it in others, rather than myself"(5). Common (physical) activities, however, do not provoke any negative experiences. No case of negative reconcilement has been reported.

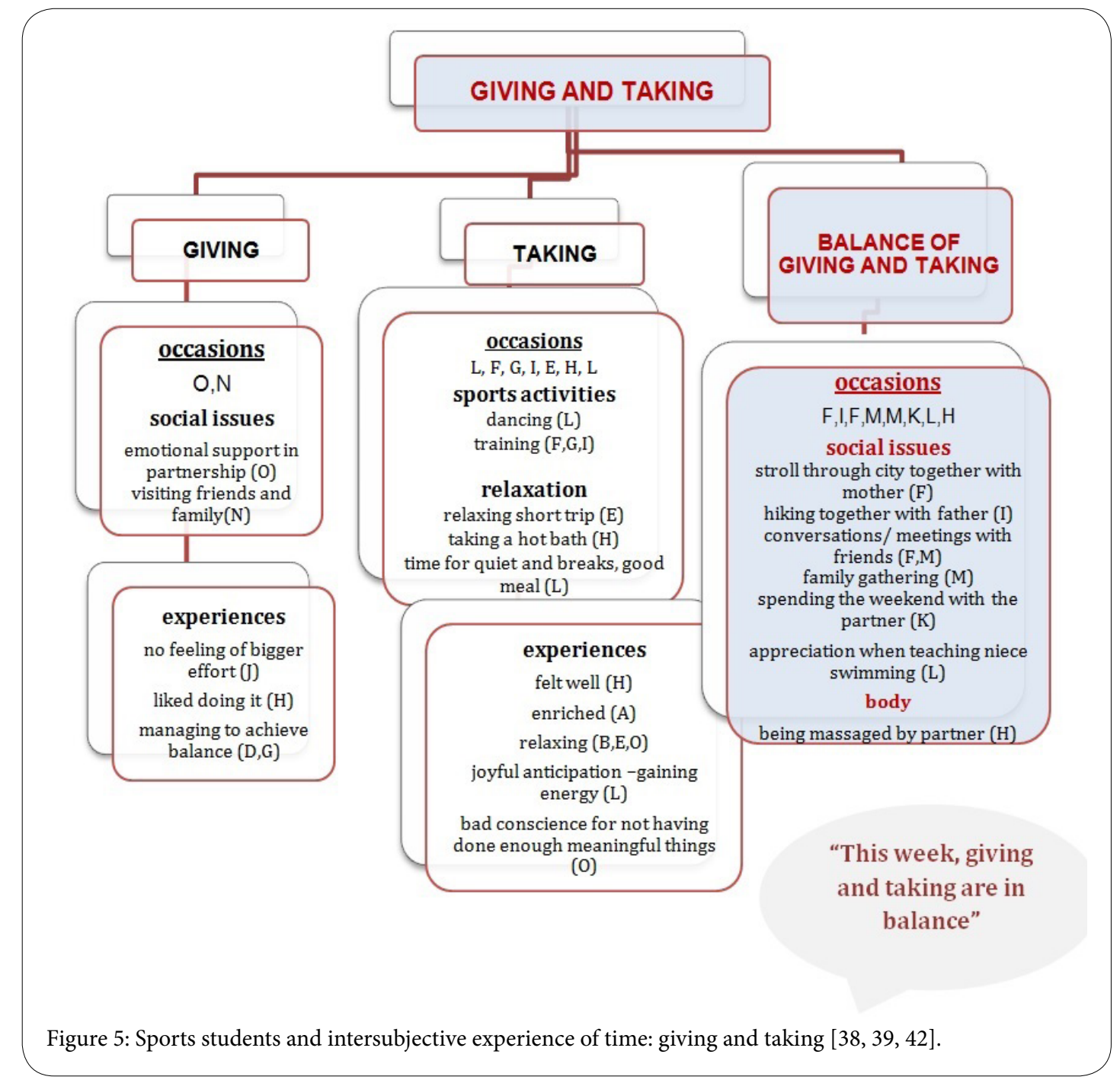


Citation: Paletta A, Suchar G, Hübler T, Juschitz D, Mayer K, et al. (2017) Time Experience of Burnout Patients: A Qualitative Diary Analysis. Int J Phys Ther Rehab 3: 126. doi: https://doi.org/10.15344/2455-7498/2017/126

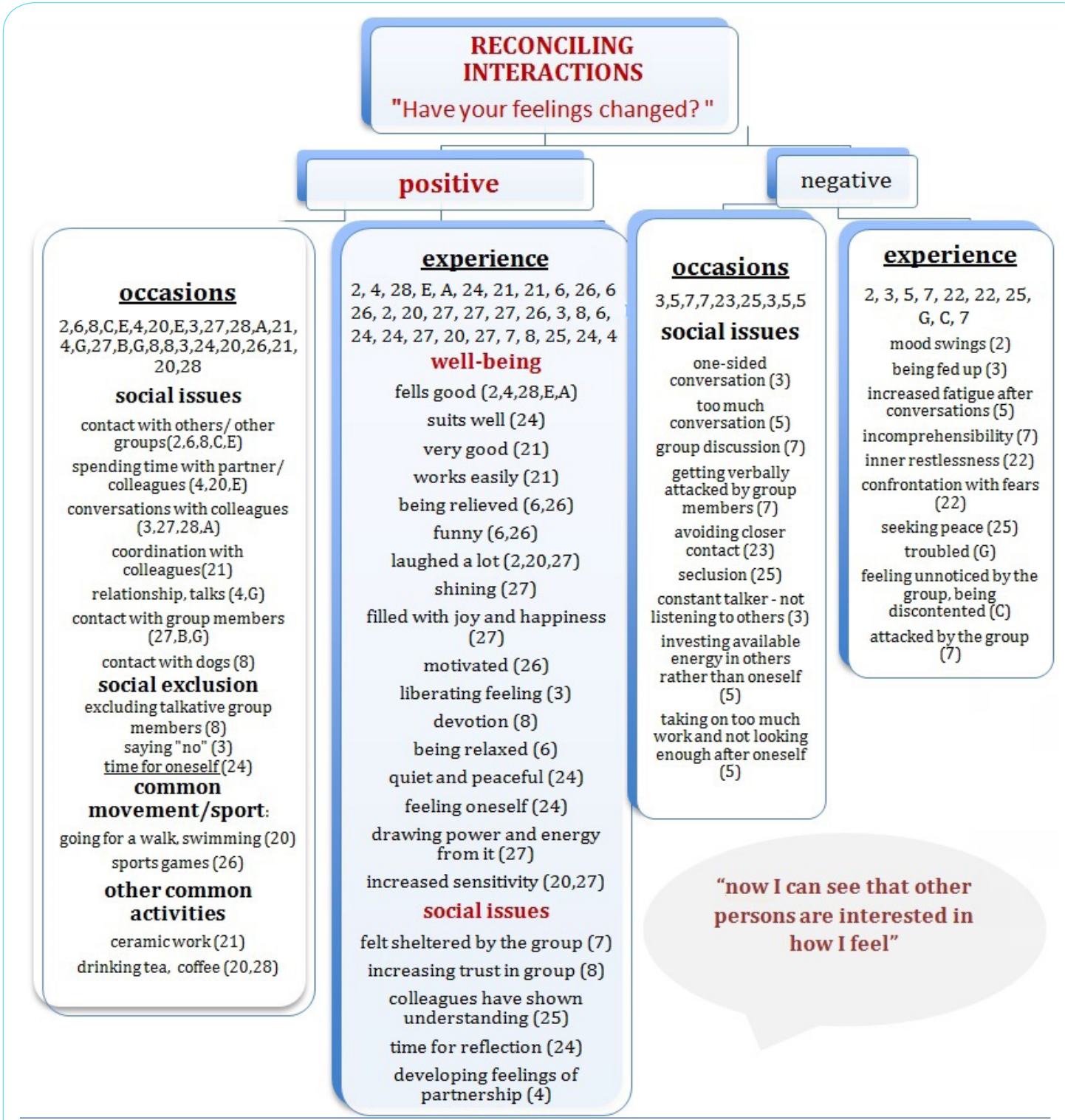

Figure 6: Burnout-patients and intersubjective experience of time: Reconcilement with others [37, 40, 41].

The statements by sports students focus more on joint social experiences, e.g. "overcoming problems together" $(\mathrm{H})$, "harmonious interactions" (L,H), "feeling that spending time together is important" $(B, G, A, C)$. The focus is on "together", regardless of the type of participants (working groups, partners, friends, relatives) and type of social interaction (sports, work, conversation). The following typical statement underlines the connection with each other: "As I like being among people, I enjoy hanging out with my three flatmates, watching TV in the living room" (A) (transl. by author). The interviewed students exclusively report positive experiences, e.g. "forgetting time", "fulfilling time" (F, M), "relaxing", "calming" and "lively" (B, F, I). No negative statements were made.

The outcome of the forth testing with burnout patients also shows positive reconcilement with others, but the representation is different than before. The main focus lies no more on self-centring but on joint conversations. The diction changes from I to we: "we have had great conversations..." (25). Moreover, fears of uncertainty arise towards the end of the therapy. However, once again the focus is not one one's self but on the group. Personal experiences are seen as part of shared experiences: "Everybody was rather tired and depressed. Everyone had kind of the same thoughts 'What is going to happen with us after therapy? The future is uncertain. Will we already be able to work under pressure? Or will it take some more time? I also ask myself these questions... "(3). At the beginning of the therapy, burnout patients experience themselves only as individual beings - in the best case supported by the group. Now, however, they are part of the group, sharing problems and anxiety about the future $[37,40]$.

The majority of interviewed sports students also report about successful reconcilement with trusted persons. The drivers of the experience are once again sports, going out and situations at work. Negative experiences are still rare $[38,39]$.

\section{Driving force: effort}

The number of situations burnout patients experience as exhausting is above average. Movement and sports in particular, but also "generally 
Citation: Paletta A, Suchar G, Hübler T, Juschitz D, Mayer K, et al. (2017) Time Experience of Burnout Patients: A Qualitative Diary Analysis. Int J Phys Ther Rehab 3: 126. doi: https://doi.org/10.15344/2455-7498/2017/126

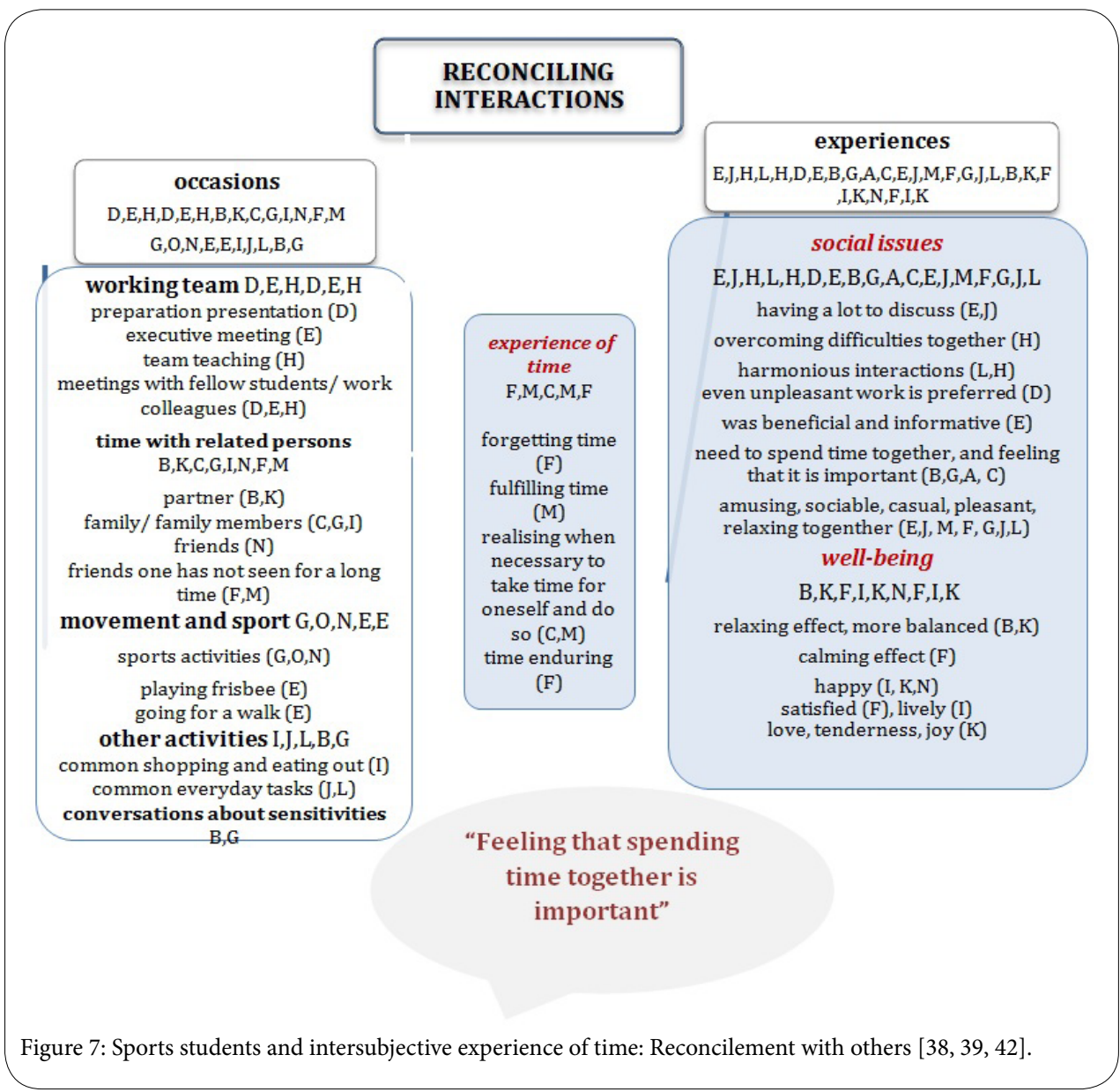

physical strain" (4) are reported as being tedious. The same applies to specific activities such as "push-ups" (7), "cross training" (20) and "going for a walk on rough ground" (8). Furthermore social get-togethers - already mentioned in connection with the intersubjective experience of time are considered as stressful, whether it is "conversations in the group" (2), "individual conversations" $(2,3)$ or "presentations" $(2)$. Even various therapies are experienced as stressful (mainly "group therapies" 8, 23). In addition to this, physical problems can also be a burden ("cardiac-atrial fibrillation" 28). Statements such as "...finally the day is over..." (5)do not come as a surprise. Negative experiences are correspondingly frequent. Burnout patients complain about "headaches" (27), "poor concentration" (2), feeling "exhausted", "annoyed" and "stressed" $(5,23,3)$. They state that they have "no more energy around midday". Positive experiences were only rarely mentioned, namely in a context of expressing objection the "liberating feeling to say 'no"' (3). Burnout patients rarely reflect on the achievement of goals as the reward for all the effort. This demonstrates that burnout patients do not focus on the achievement of goals in a manner of speaking, their efforts are pointless and without consequence.

Compared to burnout patients, sports students neverconsider making an effort as something negative. They rather see it as an investment in achieving goals. Sports students are "satisfied with performance" $(\mathrm{H}, \mathrm{I}, \mathrm{K})$, happy about "coping with tricky situations" $(\mathrm{K}, \mathrm{L})$, proud to have "met personal goals" $(\mathrm{E}, \mathrm{G}, \mathrm{K})$ and feel good about themselves - "I have exerted myself and felt lively afterwards" [36]. "I have put in a lot of effort this week. I had to deal with a tricky work- related problem. My body felt great and I had no problems at all. I have achieved my personal goals" (G). A typical statement is: "Doing sports on Monday, Wednesday and Friday, I was really able to push myself. I experienced it as a positive kind of effort. Despite the effort, my body felt very relaxed“(B).

When sports students experience that their drive is low, they do not ignore it but step back and take some time off: “... Thursday was very relaxing. I took one day off and could really recover" $(\mathrm{O})$.

Even after a five-weeklong rehabilitation stay, burnout patients still report negativelyabout their driving force. However, physical activity and social exchange are only classified as tiringhalf as many times. [30]. Self-determined intent indicates that effort is now linked with constructive goals. Statements such as "great feelings on the top of the mountain"(D), "great feeling to have mastered the challenge (25) or "making an effort to train and build up muscle"(8) and "intend to dosports at home" (22) confirm this $[37,40]$.

Sports students, however, experience a challenging week that demands even more effort than ever before. "It was exhausting to attend all university courses, which take place in different colleges." (C). Even though sports students report that they were ill, suffered injuries and therefore engaged in fewer sports activities, they still know in good time how to recharge their batteries. It should be noted that they refer to mind and body. "Just spending time with my family and friends over the weekend made me feel balanced and calm again. Finally my body was able to take a deep breath again." (A) [38, 39]. 
Citation: Paletta A, Suchar G, Hübler T, Juschitz D, Mayer K, et al. (2017) Time Experience of Burnout Patients: A Qualitative Diary Analysis. Int J Phys Ther Rehab 3: 126. doi: https://doi.org/10.15344/2455-7498/2017/126

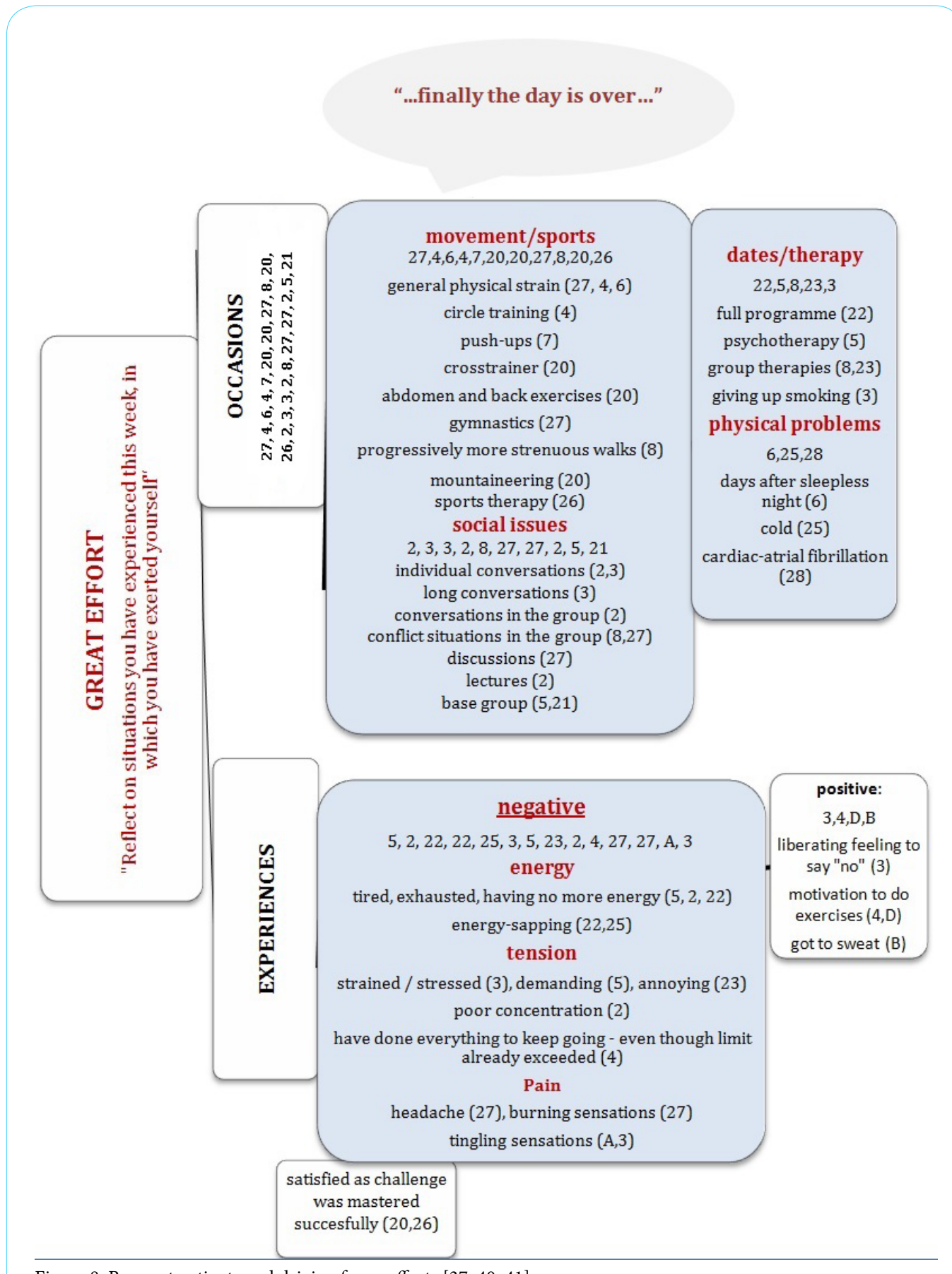

Figure 8: Burnout patients and driving force: efforts $[37,40,41]$

\section{Conclusion}

The present empirical data analyse show burnout patients and students of a sports faculty deal with the subjective time dimensions of personal rhythm, intersubjective experience of time and driving forces. This data does not only underline the considerations mentioned in chapter 2, but develops them further and reassesses connections.

The ability of finding the personal rhythm after deflections represents an important factor in terms of health stability. At the beginning of their rehabilitation stay, burnout patients complain intensively about negatively experiencing their personal rhythm. Furthermore, time schedules set by the clinic (defining rhythm from the outside) are considered to be unacceptable, but nevertheless, they don't refuse to accept them. Despite intensive complaints about fragmentation of personal time management, patients try to keep functioning and stick to the fixed pattern. In contrast, sports students consider it as very important to preserve the personal rhythm. Deflections are counteracted in due time, i.e. students respond to time pressure only when it is useful as a driver for their personal development. Already after a five week-long rehabilitation stay, half the patients report a stabilisation of their personal rhythm. They discover the pleasant effect of rhythmic activities, such as sports, on their well-being. Later on, they even mention that they practice these activities at home by 
Citation: Paletta A, Suchar G, Hübler T, Juschitz D, Mayer K, et al. (2017) Time Experience of Burnout Patients: A Qualitative Diary Analysis. Int J Phys Ther Rehab 3: 126. doi: https://doi.org/10.15344/2455-7498/2017/126

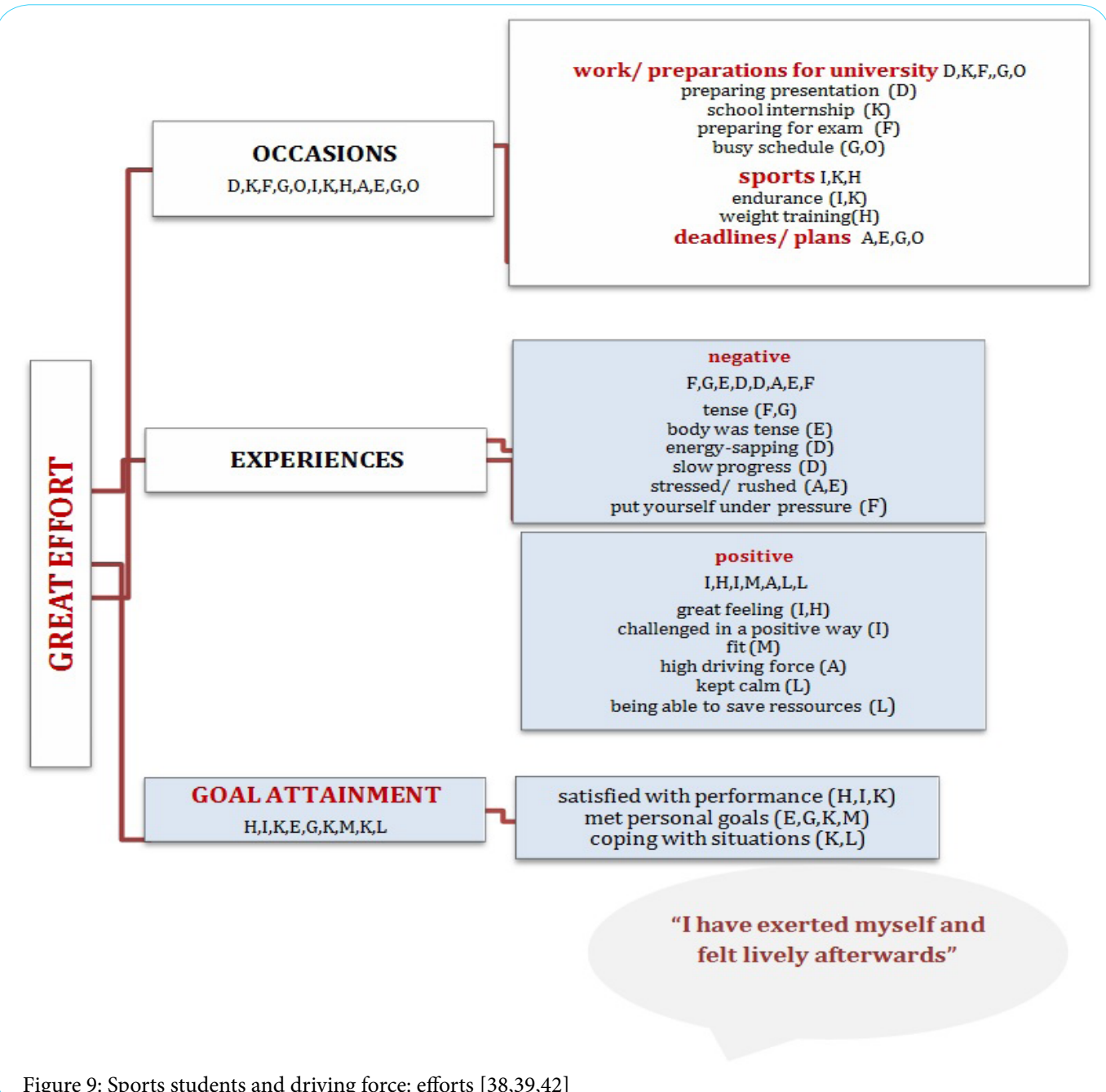

themselves. In the course of the consolidation of the personal rhythm, even time schedules set by the clinic are not experienced as annoying any more, but rather as helpful in order to establish a personal daily rhythm.

The ideal case of a successful intersubjective experience of time is a mutual adaption to each other, i.e. being in synch with each other, focusing on the feeling of togetherness. Burnout sufferers, however, do not achieve a balance between giving and taking, they tend to tilt the balance to one side. On the one hand, the permission of taking time for yourself is considered as something positive. This includes especially time for self-determined, relaxing activities (e.g. taking a hot bath). It is striking that these activities are mainly performed alone. The opposite situation, namely giving time, is experienced as negative and extremely exhausting. Patients mainly associate it with social interaction and describe it as energy-sapping. While burnout sufferers do not mention an intersubjective balance between giving and taking, this balance is the most common condition mentioned by sports students. This suggests social awareness, focusing on intersubjective response. Even after four weeks, the indicated tendencies largely remain unchanged in both groups.

Initially, the data dealing with interactions between burnout patients and their fellow citizens seems paradoxical: surprisingly, patients report about positive experiences in terms of social interactions. Closer examination shows, however, that they are only positive when the counterpart works as an intensifier of the self, that is if the counterpart puts the focus on the burnout patient and thus gives hima privileged position. While the social interaction of sports students takes place on an eye-to-eye level, this still seems impossible for patients suffering from burnout syndrome. Only in the fourth testing, burnout patients exhibit a new type of attitude, experiencing themselves as one human being among others without enjoying any special position. Now they do not completely refuse time schedules by others, but they do not accept them without questioning the meither. They will go along part of the way, then they again reflect on their inner selves. Because of this, conversations with others are not experienced as stress any more, but rather as enrichment.

Initially, two out of the three main factors of burnout patients' driving force (mental state, sense-giving, surrounding factors) have a negative connotation. Physical and mental state, as well as motivation and sense-giving, are experienced negatively. Therefore, at the beginning of the rehabilitation stay, burnout patients develop almost no driving force. Basically everything, be it sports or group therapy, is experienced as exhausting. This means that patients see them as forced measures, refuse them and do not set themselves any goals that would motivate them to invest energy in activities of any kind. Sports students interpret effort as a necessary investment in order to reach goals and draw joy from it. Burnout patients, however, experience effort as useless and meaningless, and therefore they use up much 
Citation: Paletta A, Suchar G, Hübler T, Juschitz D, Mayer K, et al. (2017) Time Experience of Burnout Patients: A Qualitative Diary Analysis. Int J Phys Ther Rehab 3: 126. doi: https://doi.org/10.15344/2455-7498/2017/126

Page 7 of 7

more energy. Nevertheless, in the course of the rehabilitation stay, more than half of the patients experience the effect of a multiplural package of activities (sports, environmental response, etc.). They also develop a consciousness for the interaction between challenges, the degree of acceptable effort and reward.

In summary it can be concluded that burnout patients at the beginning of the rehabilitation stay, when compared to the healthy control group of sports students, show remarkable deregulations concerning their personal rhythm and intersubjective experience of time, as well as diminished driving force. However, in the course of the rehabilitation stay, the patterns of burnout patients can approximate those of healthy people. It is frequently stated that movement and sports are experienced as important measures in order to extend and stabilise biological and psychosocial time patterns. These results and these perspectives of time can potentially be used as a reliable base for a specific adapted sports therapy concept.

\section{Competing Interests}

The authors declare that they have no competing interests.

\section{Ethical Approval}

All procedures performed in studies involving human participants were in accordance with the ethical standards of the institutional and/ or national research committee (GZ. 39/5/63 ex 2014/15, 08.01.2015) and with the 1964 Helsinki declaration and its later amendments or comparable ethical standards.

\section{Acknowledgements}

The project An Interdisciplinary Inquiry On Regular Body Rhythm and its Dysfunctions Nr. P 26110-G15 (R. Esterbauer, A. Paletta) was funded by the Austrian Science Fund and Austrian University Research Sector.

\section{References}

1. BKK Gesundheitsreport (2014) Krankheitstage durch das Burnout Syndrom in Deutschland.

2. BKK Bundesverband (2012) Anstieg der Fehltage durch das BurnoutSyndrom.

3. Burisch M (2014) Das Burnout-Syndrom:Theorie der inneren Erschöpfung. Heidelberg: Springer.

4. Burisch M (2014) Das Burnout-Syndrom:Theorie der inneren Erschöpfung. Heidelberg: Springer, pp. 26-29.

5. Maslach Ch, Schaufeli W, Leiter MP (2001) Job Burnout. Annu Rev Psychol 52: 397-422.

6. Fuchs Th (2013) Scheitern als Grenzsituation. Zur existenziellen Dimension des Burn-out. Symposium, Aktive Resignation - vom Umgang mit dem Unausweichlichen" am 05.09.2013 in Hohenegg.

7. Pines A. M, Aronson E, Kafry D (2007) Ausgebrannt: Vom Überdruss zur Selbstentfaltung. Stuttgart: Klett-Cotta.

8. Lazarus RS, Launier R (1981) Stressbezogene Transaktion zwischen Person und Umwelt. In: Nitsch JR (Ed): Stress - ררTheorien, Untersuchungen, Maßnahmen. Bern: Huber, pp.213-259.

9. Morgenroth O (2008) Zeit und Handeln. Psychologie der Zeitbewältigung Stuttgart: Kohlhammer

10. Lehmkuhl U Ed (2005) Die Bedeutung der Zeit: Zeiterleben und Zeiterfahrung aus Sicht der Individualpsychologie. Göttingen Vandenhoeck \& Ruprecht.
11. King V, Gerisch B (Ed) (2009) Zeitgewinn und Selbstverlust: Folgen und Grenzen der Beschleunigung. Frankfurt/New York: Campus

12. Rosa H (2005) Beschleunigung: Die Veränderung der Zeitstrukturen in der Moderne. Frankfurt/M.: Suhrkamp.

13. Geissler KA (2014) Alles hat seine Zeit, nur ich hab keine: Wege in eine neue Zeitkultur. München: Oekom Verlag.

14. Müller Th Ed (2007) Philosophie der Zeit: Neue analytische Ansätze. Frankfurt/Main: Klostermann.

15. Safranski R (2015) Zeit: was sie mit uns macht und was wir aus ihr machen. München: Hanser

16. Lehofer M, Pail G, Kasper S, Czerma C, Erfurt A, et al. (2010) Chronopsychiatrie. Neustadt/Aisch: Plötz.

17. Li JZ, Bunney BG, Meng F, et.al. (2014) PNAS 110: pp. 9950-9955

18. Schöneck NM (2009) Zeiterleben und Zeithandeln Erwerbstätiger: Eine methodenintegrative Studie. Wiesbaden: VS Verlag für Sozialwissenschaften, pp.40,41

19. Blasche G M, Pfeffer M, Thaler H, Gollner E (2013) Work-site health promotion of frequent computer users: Comparing selected interventions. Work 46: 233-241.

20. Pauleikhoff B (1979) Person und Zeit: Im Brennpunkt seelischer Störungen. Heidelberg: Hüthig

21. Klages W (1967) Der menschliche Antrieb: Psychologie und Psychopathologie. Stuttgart: Thieme.

22. Wölk M (2009) Gelebte Zeit im Stillstand und Sprung: Angst und Spontaneität als Konstituenten von Melancholie und Manie. J Philosophie \& Psychiatrie $2: 1-18$

23. Fuchs T (2009) Psychopathologie der subjektiven und intersubjektiven Zeitlichkeit. J Philosophie \& Psychiatrie 2: 1-27.

24. Csikszentmihalyi M (2003) Flow. Stuttgart: Klett-Cotta.

25. Paletta A (2016) Spare an der Zeit, so hast du sicher Not: Einführung in Entgleisungen der Zeiterfahrung im Burnout.In: Esterbauer R, Paletta A Schmidt Ph, Duncan D (Ed) Bodytime: Leib und Zeit bei Burnout und in anderen Grenzerfahrungen. Freiburg/München: Alber

26. Onken M (2013) Bis nichts mehr ging: Protokoll eines Ausstiegs. Reinbek Hamburg: Rowohlt, p 11.

27. Meckel M (2011) Brief an mein Leben: Erfahrungen mit einem Burnout. Reinbek bei Hamburg: Rowohlt, p 81.

28. Meckel M (2011) Brief an mein Leben: Erfahrungen mit einem Burnout Reinbek bei Hamburg: Rowohlt, p 66.

29. Meckel M (2011) Brief an mein Leben: Erfahrungen mit einem Burnout. Reinbek bei Hamburg: Rowohlt, p 49.

30. Susuli,in:https://www.burn-out-forum.de/forum/66/13829 posted19.07.2014

31. Klages W (1967) Der menschliche Antrieb: Psychologie und Psychopathologie. Stuttgart: Thieme, p 10,11

32. Fischer D, Bosse D (2010) Das Tagebuch als Lern- und Forschungsinstrument. In Friebertshäuser B, Langer A, Prengel A (Ed) Handbuch qualitative Forschungsmethoden in der Erziehungswissenschaft. Weinheim/München: Juventa, pp 875-876.

33. Hagemann W, Geuenich K (2009) Burnout-Screening-Skalen(BOSS). Manual. Göttingen: Hogrefe.

34. Mayring Ph (2010) Methodologische Ziellinien und Designs qualitativpsychologischer Studien: Design. In Mey G, Mruck K (Ed) Handbuch Qualitative Forschung in der Psychologie. Wiesbaden: Springer, pp225238.

35. Paletta A (2013) Kommt Zeit kommt Rat: Zeiterfahrung im Unterrichtsfach Sport und Bewegung. In Sportunterricht 62: 209-214. 
Citation: Paletta A, Suchar G, Hübler T, Juschitz D, Mayer K, et al. (2017) Time Experience of Burnout Patients: A Qualitative Diary Analysis. Int J Phys Ther Rehab 3: 126. doi: https://doi.org/10.15344/2455-7498/2017/126

Page 7 of 7

36. Mayer K, Paletta A (2015) Einszweidrei, im Sauseschritt läuft die Zeit - wir laufen mit (W. Busch): Zeiterfahrung bei Sportstudierenden - eine qualitative Studie. In Bewegung und Sport 5: 21-27

37. Hübler Th (2016) Zeiterfahrung von Burnout-PatientInnen: Eine qualitative Tagebuch-Analyse. Masterarbeit Univ. Graz.

38. Mayer K (2015) Faktoren subjektiver und intersubjektiver Zeit- und Körpererfahrung bei Sportstudierenden. Diplomarbeit Univ. Graz.

39. Staltner J (2015) Aspekte der Zeit- und Körpererfahrung von Sportstudierenden in Tagebüchern: Eine qualitative Studie. Diplomarbeit Univ. Graz.

40. Juschitz D (2016) Zeit und Körpererfahrung von Burn-out Patienten: Eine Qualitative Untersuchung in Form von Tagebüchern. Diplomarbeit Univ. Graz

41. Paletta A, Hübler Th, Juschitz D (2015) Archive diary burnoutpatients. Graz

42. Paletta A, Mayer K, Staltner J (2015) Archive diary sport students. Graz. 